\title{
ALFABETIZAÇÃO DE CRIANÇAS: concepções e perspectivas
}

\author{
Juliana Stephan Lucon' \\ Marli Lúcia Tonatto Zibetti2
}

\section{RESUMO}

Neste artigo, expõem-se os resultados de um levantamento bibliográfico, cujo objetivo foi compreender como o campo da alfabetização de crianças tem sido estudado nos últimos anos no Brasil. Nesse levantamento, procurou-se identificar: as concepções teóricas que sustentam os trabalhos publicados, os temas que foram objeto de análise, bem como as lacunas que têm exigido maior atenção dos pesquisadores. No site da Associação Nacional de Pesquisa e Pós-Graduação em Educação (ANPED) e no repositório da Scientific Electronic Library Online (Scielo) estão as bases de dados consultadas para esse levantamento. Delimitando-se ao período de 2011 a 2017, foram lidos integralmente 21 artigos. Os resultados indicam que a maior parte da produção é oriunda das regiões Sudeste e Nordeste, de pesquisas desenvolvidas em programas de pós-graduação. Quanto aos referenciais teóricos, apesar da grande diversidade, constatou-se o predomínio de enfoques da psicogênese da língua escrita e do letramento. Constatou-se também que a perspectiva teórica da psicologia histórico-cultural começa a fundamentar algumas produções. Quanto às temáticas, os dados indicaram grande heterogeneidade: foram mais abordadas, em ordem, a aprendizagem da leitura e da escrita e as práticas pedagógicas utilizadas para alfabetizar. Os resultados evidenciam que os temas que precisam de maior atenção são: a alfabetização de crianças com deficiência, o uso da tecnologia, a alfabetização em contextos de diversidade cultural, como as comunidades indígenas e quilombolas, e a avaliação dos processos de ensino e aprendizagem da língua escrita.

Palavras-chave: Aprendizagem. Leitura. Escrita.

\section{CHILD LITERACY: conceptions and perspectives}

\begin{abstract}
This article results from the bibliographic survey aimed at understanding how the field of child literacy has been studied in recent years in Brazil, identifying theoretical conceptions that support the published works, the themes that were the object of analysis, as well as gaps that require greater attention of researchers. The website of the National Association for Research and Postgraduate Education (ANPED) and the

\footnotetext{
1 Mestra em Psicologia pela Universidade Federal de Rondônia, Porto Velho, Rondônia, Brasil. Orcid iD: https://orcid.org/0000-0001-9245-5237. E-mail: jujulucon@hotmail.com

2 Doutorado em Psicologia Escolar e Desenvolvimento Humano. Professora da Universidade Federal de Rondônia, Porto Velho, Rondônia, Brasil. Orcid iD: https://orcid.org/0000-00033939-5663. E-mail: marlizibetti@yahoo.com.br
} 
repository of the Online Scientific Electronic Library (Scielo) were as databases consulted for this exam, with the return of 21 articles read in full, under delimited consultation to the period from 2011 to 2017. The results that result in most of the production come from the southeast and northeast regions and decorate researches researched in postgraduate programs. Regarding the theoretical references, it is noted the great diversity, with a predominance of psychological focus in the written language and without literacy. A theoretical perspective of historical-cultural psychology begins to ground some productions. Regarding the themes, the data indicate great heterogeneity, being more approached in reading and writing learning, followed by the pedagogical practices used to literacy. The results show that the themes that require the most attention are the literacy of children with disabilities; use of technology and literacy in culturally diverse contexts, such as the countryside, indigenous and quilombola communities, as well as evaluation in the teaching and learning processes of written language.

Keywords: Learning. Reading. Writing.

\section{ALFABETIZACIÓN INFANTIL: concepciones y perspectivas}

\section{RESUMEN}

Este artículo es el resultado de la encuesta bibliográfica dirigida a comprender cómo se ha estudiado el campo de la alfabetización infantil en los últimos años en Brasil, identificando concepciones teóricas que respaldan los trabajos publicados, los temas que fueron objeto de análisis, así como las brechas que requieren mayor atención de investigadores. El sitio web de la Asociación Nacional de Investigación y Educación de Postgrado (ANPED) y el repositorio de la Biblioteca Electrónica Científica en Línea (Scielo) fueron las bases de datos consultadas para este relevamiento, con la devolución de 21 artículos leídos en su totalidad, bajo consulta delimitada al período de 2011 a 2017. Los resultados dan como resultado que la mayor parte de la producción proviene de las regiones sureste y noreste y de investigaciones desarrolladas en programas de posgrado. En cuanto a las referencias teóricas, se destaca la gran diversidad, con predominio del enfoque psicológico en el lenguaje escrito y sin alfabetización. Una perspectiva teórica de la psicología histórico-cultural comienza a fundamentar algunas producciones. Con respecto a los temas, los datos indican una gran heterogeneidad, siendo más abordados en el aprendizaje de lectura y escritura, seguidos de las prácticas pedagógicas utilizadas para la alfabetización. Los resultados muestran que los temas que requieren mayor atención son la alfabetización de los niños con discapacidades; uso de la tecnología y la alfabetización en contextos culturalmente diversos, como el campo, las comunidades indígenas y quilombolas, así como la evaluación en los procesos de enseñanza y aprendizaje del lenguaje escrito.

Palabras clave: Aprendizaje. Lectura. Escritura. 


\section{SITUANDO A TEMÁTICA}

Segundo Soares (2004), até as décadas de 1950 e 1970 no Brasil, as discussões educacionais sobre o ensino da leitura e da escrita centravam-se mais na busca do melhor método para ensinar. Considerava-se então que o fracasso escolar na alfabetização estava relacionado a metodologias inadequadas. Nesse período, os métodos mais difundidos eram o global e o fonético.

No método global, ou analítico, considerava-se melhor iniciar a alfabetização por pequenos textos ou frases para que, a partir da visão global, se entendessem as partes (sílabas e letras).

No método fonético, ou sintético, propunha-se que, inicialmente, fosse promovido o aprendizado das letras, das sílabas e do som para, depois, incluir palavras, frases e textos. Nessa concepção, a aprendizagem da leitura e da escrita era fundada na cópia, na memorização e na associação entre grafemas e fonemas.

Como o centro da atuação era o método, o docente não era orientado a observar o processo de aprendizagem das crianças; assim, suas intervenções e orientações pedagógicas eram semelhantes para todas elas, em conformidade com os passos previstos no método adotado.

No início da década de 1980, juntamente com a luta pela ampliação de acesso à escola pública, as críticas ao fracasso da escola na alfabetização de crianças foram fortalecidas com a disseminação das ideias construtivistas.

[...] introduziu-se no Brasil o pensamento construtivista sobre alfabetização, resultante das pesquisas sobre a psicogênese da língua escrita desenvolvidas pela pesquisadora argentina Emília Ferreiro e colaboradores. Deslocando o eixo das discussões dos métodos de ensino para o processo de aprendizagem da criança (sujeito cognoscente), o construtivismo se apresenta, não como um método novo, mas como uma "revolução conceitual", demandando, dentre outros aspectos, abandonarem-se as teorias e práticas tradicionais, desmetodizar-se o processo de alfabetização e se questionar a necessidade das cartilhas (MORTATTI, 2006, p. 10). 
As pesquisas de Emília Ferreiro e Ana Teberosky (1985) sobre a psicogênese da língua escrita provocaram grandes transformações nas concepções e nas práticas da alfabetização infantil no Brasil. Na revolução conceitual a que se refere Mortatti, a ênfase nos métodos de ensino é transferida para a compreensão do pensamento infantil sobre a leitura e a escrita. Ao mesmo tempo, a memorização e a realização de atividades mecânicas, conforme sequência estabelecida nas cartilhas adotadas em cada escola, cedem lugar para o estímulo à ação do sujeito cognoscente, conforme suas possibilidades de assimilação.

Na teoria de Piaget, então, um mesmo estímulo (ou objeto) não é o mesmo, a menos que os esquemas assimiladores à disposição também o sejam. Isto equivale a colocar o sujeito da aprendizagem no centro do processo, e não aquele que, supostamente, conduz essa aprendizagem (o método, na ocasião, ou quem o veicula) (FERREIRO; TEBEROSKY, 1985, p.30).

No entanto, os altos índices do fracasso escolar na alfabetização se mantiveram, levando a uma ampliação dos estudos nesse campo e à produção de novas concepções de ensino, nas quais se destacam críticas à proposta construtivista. As principais críticas incidiram sobre a transposição, para a sala de aula, dos processos de construção da leitura e da escrita, conforme explicitados na psicogênese da língua escrita, sem que os docentes tivessem conhecimento amplo da teoria, o que teria levado a práticas que desvalorizam o ato de ensinar. $\mathrm{O}$ abandono de métodos, com passos pré-estabelecidos, em favor da observação do processo de aprendizagem infantil, foi denominado como desmetodização da alfabetização porque incluía a crença de que o aluno aprenderia apesar dos métodos, desde que the fosse oportunizado contato com a língua escrita.

Na busca por superar o fracasso escolar no ensino da leitura e da escrita e fundamentadas nas contribuições da linguística, Tfouni (1995), Kleiman $(1995)$ e Soares $(1989 ; 1998 ; 2004)$ apresentaram novas contribuições ao ensino da leitura e da escrita, diferenciando o processo de letramento do 
processo de alfabetização. Segundo Soares (2004), embora sejam indissociáveis, esses processos são distintos: o termo alfabetização se restringe à habilidade de decodificar a língua, enquanto o letramento refere-se à inserção dos aprendizes nos usos sociais do ler e escrever.

Outra perspectiva teórica que contribui para 0 ensino e a aprendizagem na alfabetização é a psicologia histórico-cultural. Fundamentados nos estudos de Vigotski e colaboradores, os defensores dessa perspectiva frisam a intencionalidade do ensino, a mediação do professor e a efetiva participação do aluno para se apropriar do que the é ensinado. Vigotskii (2012) assevera que o ensino intencional voltado para o desenvolvimento das funções psicológicas superiores gera saltos qualitativos que alteram radicalmente o conteúdo e a forma do pensamento da criança.

Na psicologia histórico-cultural, a linguagem escrita é entendida como instrumento de desenvolvimento psíquico. Antes de dominar a escrita simbólica, a criança percorre diferentes estágios, como os gestos, os desenhos, as brincadeiras e os rabiscos. Vigotskii (2012) e Luria (2012) confirmaram em suas pesquisas que esses estágios conduzem à futura escrita da criança.

Nesse sentido, o professor assume papel fundamental no processo de ensino: sua intervenção é imprescindível para garantir que a criança se aproprie da linguagem escrita como objeto cultural. De acordo com Tuleski e Chaves (2011 , p. 218), "[...] devemos ensinar a técnica, a relação grafemafonema e ampliar seu universo vocabular, explorando em sala de aula diversas formas de narrativas escritas". Para as autoras, é preciso lembrar que a linguagem escrita é um objeto de conhecimento cultural complexo, desafiador e repleto de convenções e arbitrariedades. O êxito de seu ensino depende de um professor preparado e de condições adequadas de trabalho.

Enfim, este breve histórico mostra que o campo da alfabetização das crianças no Brasil tem sido fértil em perspectivas teóricas, cujas influências aparecem em documentos curriculares, programas de formação docente e, 
consequentemente, nas práticas pedagógicas desenvolvidas nas escolas. Alguns problemas parecem ter sido superados e outros estão no centro das preocupações de educadores e pesquisadores, exigindo que, periodicamente, se façam a análise e a síntese das produções científicas e se identifiquem os aspectos que exigem maior investimento nesse campo de estudo.

\section{MÉTODO}

Com o presente levantamento, buscou-se entender como o campo da alfabetização tem sido estudado nos últimos anos no Brasil e apontar as concepções teóricas que sustentam os trabalhos publicados, os temas que foram objeto de análise, bem como as lacunas que exigem maior atenção dos pesquisadores.

O levantamento de publicações científicas sobre ensino e aprendizagem da leitura e escrita foi realizado com base em dois repositórios importantes: os artigos publicados entre os anos 2013 e 2017 no SciELO (Scientific Eletronic Library OnLine) e os documentos das reuniões $34^{a}$ a $38^{a}$ do GT 10 - Alfabetização, leitura e escrita contidos na página da Associação Nacional de Pesquisa e Pós-Graduação em Educação (ANPED).

A escolha dessas bases de dados explica-se por sua relevância no meio acadêmico e por conter publicações no formato de artigos, que primam pela concisão e pela submissão à revisão sistemática de pares.

Como a página da ANPED não permitia a busca por indexadores, a seleção foi baseada na leitura dos títulos contidos em cada seção dos trabalhos do GT 10. Do total de 84 artigos, 19 tratavam do ensino e da aprendizagem da leitura e da escrita em classes/séries de alfabetização. Muitos títulos não ofereciam informações suficientes do conteúdo, por isso foram lidos os resumos, atentando para os métodos e os resultados dos trabalhos. Descartando-se os textos voltados à Educação Infantil, Ensino Fundamental II e Educação de Jovens e Adultos (EJA), foram selecionados 14 trabalhos. 
O levantamento das produções no SciELO deu-se em duas etapas, com cruzamento de termos:

1. "Aprendizagem da leitura e escrita" e "crianças": esse cruzamento resultou em 32 artigos. Após a leitura dos resumos, foram selecionados seis trabalhos cujos temas se relacionavam ao ensino e à aprendizagem da leitura e da escrita em séries de alfabetização. Os outros foram descartados porque não abordavam o tema do ensino ou aprendizagem de crianças.

2. Por meio do cruzamento das palavras-chave "letramento", "leitura escrita" e "crianças", foram identificados cinco trabalhos. Após a leitura dos resumos foram selecionados outros dois trabalhos, um dos quais também havia sido encontrado no repositório da ANPED. Um terceiro cruzamento foi feito com os termos "Alfabetização", "leitura e escrita" e "crianças", mas a busca não retornou resultados.

Dessa forma, foram incluídas sete publicações do SciElo na pesquisa.

Os trabalhos selecionados foram lidos na íntegra e os resultados estão apresentados na próxima seção.

\section{RESULTADOS E DISCUSSÕES}

No quadro 1, apresentamos dados de identificação dos 21 trabalhos selecionados, 14 do repositório da ANPED e sete do SciElo: títulos, autores, origem da produção, instituição em que foram produzidos e ano de produção.

Quadro 1- Identificação dos trabalhos

\begin{tabular}{|c|c|c|c|c|}
\hline & Título & Autor & Origem & $\begin{array}{l}\text { IES e } \\
\text { ano }\end{array}$ \\
\hline \multicolumn{5}{|c|}{ ANPED } \\
\hline 1 & $\begin{array}{l}\text { A alfabetização e sua relação com } \\
\text { o uso do computador: o suporte } \\
\text { digital como mais um instrumento de } \\
\text { ensino-aprendizagem da escrita. }\end{array}$ & $\begin{array}{l}\text { GLÓRIA, Julianna Silva; } \\
\text { FRADE, Isabel Cristina } \\
\text { Alves da Silva. }\end{array}$ & Tese & $\begin{array}{l}\text { UFMG, } \\
2011\end{array}$ \\
\hline 2 & $\begin{array}{l}\text { O conhecimento de letras e sua } \\
\text { relação com a aprendizagem da } \\
\text { escrita alfabética. }\end{array}$ & $\begin{array}{l}\text { LEITE, Tânia Maria Soares } \\
\text { Bezerra Rios. }\end{array}$ & Tese & $\begin{array}{l}\text { UFPE, } \\
2011\end{array}$ \\
\hline 3 & $\begin{array}{l}\text { A relação entre as práticas de } \\
\text { alfabetização e as aprendizagens } \\
\text { das crianças nos três anos iniciais do }\end{array}$ & $\begin{array}{l}\text { CRUZ, Magna do Carmo } \\
\text { Silva; ALBUQUERQUE, } \\
\text { Eliana Borges Correia. }\end{array}$ & Tese & $\begin{array}{l}\text { UFPE, } \\
2012\end{array}$ \\
\hline
\end{tabular}

Revista Exitus, Santarém/PA, Vol. 10, p. 01-25, e020032, 2020. 


\begin{tabular}{|c|c|c|c|c|}
\hline & $\begin{array}{l}\text { ensino fundamental em escolas } \\
\text { organizadas em série e em ciclos. }\end{array}$ & & & \\
\hline 4 & $\begin{array}{l}\text { Práticas de alfabetização e } \\
\text { letramento: o fazer pedagógico de } \\
\text { uma alfabetizadora bem sucedida. }\end{array}$ & $\begin{array}{l}\text { SOUZA, Ivânia Pereira } \\
\text { Midon; CARDOSO, } \\
\text { Cancionila Janzkovski. }\end{array}$ & Dissertação & $\begin{array}{l}\text { UFMT, } \\
2012\end{array}$ \\
\hline 5 & $\begin{array}{l}\text { A concepção de leitura de } \\
\text { professoras alfabetizadoras e a sua } \\
\text { influência no ensino do ato de ler. }\end{array}$ & CORREIA, Joelma Reis. & Tese & $\begin{array}{l}\text { UFMA, } \\
2013\end{array}$ \\
\hline 6 & $\begin{array}{l}\text { Leitura, compreensão e produção } \\
\text { textuais: progressão desses eixos de } \\
\text { ensino de língua portuguesa no } 1^{\circ} \\
\text { ciclo. }\end{array}$ & OLIVEIRA, Solange Alves. & Artigo & $\begin{array}{l}\text { UnB } \\
2013\end{array}$ \\
\hline 7 & $\begin{array}{l}\text { O desafio do "alfabetizar letrando" } \\
\text { em sala de aula: um estudo de } \\
\text { caso. }\end{array}$ & $\begin{array}{l}\text { MELO, Terezinha Toledo } \\
\text { Melquíades; } \\
\text { MAGALHÃES, Luciane } \\
\text { Manera. }\end{array}$ & Dissertação & $\begin{array}{l}\text { UFJF, } \\
2013\end{array}$ \\
\hline 8 & $\begin{array}{l}\text { O ensino da língua portuguesa na } \\
\text { alfabetização inicial: tempos e } \\
\text { contratempos. }\end{array}$ & $\begin{array}{l}\text { MAGALHÃES, LUciane } \\
\text { Manera; MULLER, Analina } \\
\text { Alves de Oliveira. }\end{array}$ & Artigo & $\begin{array}{l}\text { UFJF, } \\
2015\end{array}$ \\
\hline 9 & $\begin{array}{l}\text { Da sala de Dona Benta para a sala } \\
\text { de aula: contribuições para pensar } \\
\text { a mediação da leitura literária na } \\
\text { escola. }\end{array}$ & TRAVASSOS, Sônia. & Dissertação & $\begin{array}{l}\text { UFRJ, } \\
2015\end{array}$ \\
\hline 10 & $\begin{array}{l}\text { Os livros para o ensino inicial da } \\
\text { leitura e da escrita utilizados como } \\
\text { apoio na preparação das aulas: um } \\
\text { estudo a partir de cadernos de } \\
\text { planejamentos de uma professora } \\
\text { alfabetizadora (1983-2000). }\end{array}$ & VIEIRA, Cícera Marcelina. & Dissertação & $\begin{array}{l}\text { UFPEL, } \\
2015\end{array}$ \\
\hline 11 & $\begin{array}{l}\text { Construções cotidianas de práticas } \\
\text { de alfabetização e o ensino } \\
\text { sistemático da escrita: elementos da } \\
\text { formação continuada mobilizados } \\
\text { por professoras. }\end{array}$ & GAMA, Ywanoska. & Tese & $\begin{array}{l}\text { UFPE, } \\
2015\end{array}$ \\
\hline 12 & $\begin{array}{l}\text { Práticas de alfabetização em turmas } \\
\text { multisseriadas: estratégias docentes } \\
\text { para lidar com a heterogeneidade } \\
\text { de aprendizagens. }\end{array}$ & $\begin{array}{l}\text { SÁ, Carolina Figueiredo } \\
\text { de; PESSOA, Ana Cláudia } \\
\text { Rodrigues Gonçalves. }\end{array}$ & Dissertação & $\begin{array}{l}\text { UFPE, } \\
2015\end{array}$ \\
\hline 13 & $\begin{array}{l}\text { Alfabetização emancipadora com } \\
\text { crianças: "artesanar" leituras da } \\
\text { palavramundo. }\end{array}$ & $\begin{array}{l}\text { AIRE, Franciane Sousa } \\
\text { Ladeira. }\end{array}$ & Dissertação & $\begin{array}{l}\text { UFSJ, } \\
2017\end{array}$ \\
\hline 14 & $\begin{array}{l}\text { Práticas de ensino de leitura literária } \\
\text { nos anos iniciais: interações opacas, } \\
\text { sentidos dissipados. }\end{array}$ & $\begin{array}{l}\text { NASCIMENTO, Iracema } \\
\text { Santos do. }\end{array}$ & Tese & $\begin{array}{l}\text { FEUSP, } \\
2017\end{array}$ \\
\hline \multicolumn{5}{|c|}{ SCIELO } \\
\hline 15 & $\begin{array}{l}\text { Alfabetização: o olhar das crianças } \\
\text { sobre o aprendizado da linguagem } \\
\text { escrita. }\end{array}$ & $\begin{array}{l}\text { GONÇALVES, Angela } \\
\text { Vidal. }\end{array}$ & Dissertação & $\begin{array}{l}\text { UFF, } \\
2013\end{array}$ \\
\hline 16 & $\begin{array}{l}\text { A aprendizagem da escrita e a } \\
\text { escolaridade materna. }\end{array}$ & $\begin{array}{lc}\text { FERREIRA, } & \text { Amanda de } \\
\text { Andrade; } & \text { SILVA, Ana } \\
\text { Carolinar } \quad \text { Francisca; } \\
\text { QUEIROGA, Bianca } \\
\text { Arruda Manchester. }\end{array}$ & Artigo & $\begin{array}{l}\text { UFPE, } \\
2014\end{array}$ \\
\hline 17 & $\begin{array}{l}\text { Fatores socioculturais envolvidos no } \\
\text { processo de aquisição da } \\
\text { linguagem escrita. }\end{array}$ & $\begin{array}{l}\text { LEITE, Karoline Kussik de } \\
\text { Almeida; } \\
\text { BITTENCOURT, Zélia Zilda }\end{array}$ & TCC & $\begin{array}{l}\text { Uni } \\
\text { camp, } \\
2015\end{array}$ \\
\hline
\end{tabular}




\begin{tabular}{|c|c|c|c|c|}
\hline & & $\begin{array}{l}\text { L. de Camargo; SILVA, } \\
\text { Ivani Rodrigues. }\end{array}$ & & \\
\hline 18 & $\begin{array}{l}\text { As práticas pedagógicas e } 0 \\
\text { material didático do programa ler e } \\
\text { escrever no } 1^{\circ} \text { ano do ensino } \\
\text { fundamental. }\end{array}$ & $\begin{array}{l}\text { SANTOS, Tatiana Cristina. } \\
\text { TASSONI, Elvira Cristina } \\
\text { Martins. }\end{array}$ & Dissertação & $\begin{array}{l}\text { Puc- } \\
\text { Campi } \\
\text { nas, } \\
2015 \\
\end{array}$ \\
\hline 19 & $\begin{array}{l}\text { Conhecimento metalinguístico e } \\
\text { aprendizagem da leitura e da } \\
\text { escrita. }\end{array}$ & $\begin{array}{l}\text { GAIOLAS, Mónica } \\
\text { Sampaio; MARTINS, } \\
\text { Margarida Alves. }\end{array}$ & Tese & $\begin{array}{l}\text { ISPA, } \\
2017\end{array}$ \\
\hline 20 & $\begin{array}{l}\text { Práticas de alfabetização com } \\
\text { crianças de seis anos no ensino } \\
\text { fundamental: diferentes estratégias, } \\
\text { diferentes concepções. }\end{array}$ & $\begin{array}{l}\text { MACEDO, Maria do } \\
\text { Socorro Alencar Nunes; } \\
\text { ALMEIDA, Ana Caroline; } \\
\text { TIBÚRCIO, Ana Paula do } \\
\text { Amaral. }\end{array}$ & Artigo & $\begin{array}{l}\text { UFPE; } \\
\text { UFSJ, } \\
2017\end{array}$ \\
\hline 21 & $\begin{array}{l}\text { Intervenção mediacional na } \\
\text { aprendizagem do braille: um estudo } \\
\text { com crianças deficientes visuais. }\end{array}$ & $\begin{array}{l}\text { DIONÍSIO, Ana Maria } \\
\text { Pereira; VECTORE, Celia. }\end{array}$ & Dissertação & $\begin{array}{l}\text { UFU, } \\
2017\end{array}$ \\
\hline
\end{tabular}

Fonte: Elaborado pelas pesquisadoras com base em levantamento bibliográfico nos sites da ANPED e SCIELO.

Das produções analisadas, 18 são oriundas de pesquisas realizadas em universidades federais, duas de universidades privadas e uma de um instituto universitário. Sete desses trabalhos são derivados de pesquisas de doutorado, nove de pesquisas de mestrado, um trabalho foi produzido como conclusão do curso de graduação e somente quatro foram elaborados como artigos científicos. Ou seja, dos 21 artigos selecionados, apenas quatro não resultaram de cursos de formação acadêmica, o que implica que essa produção tem marcas determinadas que precisam ser consideradas. Em sua maioria, os estudos foram desenvolvidos por pesquisadores iniciantes, caracterizando-se como pesquisas individuais sobre recortes específicos da temática e produzidos em tempo exíguo.

Somente um artigo (GAIOLAS; MARTINS, 2017) é internacional; os demais são oriundos das diversas regiões do Brasil, especialmente do Sudeste (doze pesquisas) e do Nordeste (sete pesquisas). A região Centro-Oeste está representada pela Universidade de Brasilia (UnB) e pela Universidade Federal do Mato Grosso (UFMT). Na região Sul, uma pesquisa foi realizada na Universidade Federal de Pelotas no Rio Grande do Sul (UFPEL). Nesse levantamento, não foram encontradas contribuições das instituições da Região Norte. 
Levantamentos realizados por Ribeiro (2011), Goulart, Schwartz e Maciel (2015) e Lupassa (2015) também indicam que a maior produção está concentrada nas regiões Sudeste e Nordeste e que é expressiva a produção da UFPE na temática da alfabetização.

Constatamos que todas as autoras dos trabalhos selecionados para nosso estudo são mulheres. Uma hipótese de explicação para esse resultado refere-se à construção social dos papeis realizados por homens e mulheres na educação das crianças: comumente, a docência nas etapas de educação infantil e ensino fundamental tem sido assumida por mulheres. Conforme Zibetti e Souza (2007, p. 23), a responsabilidade de educar as crianças tem sido atribuída às mulheres: "[...] missão feminina desde o período de consolidação como profissão até os dias atuais em que se constata flagrantemente a maioria de mulheres nesta função".

No Quadro 2, são apresentados, pela ordem do primeiro quadro, os referenciais teóricos utilizados nos respectivos trabalhos.

Quadro 2 - Referenciais teóricos

\begin{tabular}{|c|l|}
\hline Ordem & \multicolumn{1}{|c|}{ Referencial } \\
\hline 1 & $\begin{array}{l}\text { Letramento e multimodalidades de Street; psicogênese da língua escrita de } \\
\text { Ferreiro e Teberosky. }\end{array}$ \\
\hline 2 & $\begin{array}{l}\text { Psicogênese da escrita de Ferreiro e Teberosky. } \\
\text { Psicogênese da língua escrita de Ferreiro e Teberosky; Arroyo e a configuração } \\
\text { das escolas. }\end{array}$ \\
\hline 4 & Alfabetização e letramento: Magda Soares. \\
\hline 5 & $\begin{array}{l}\text { Bakhtin; Vygotsky; estudiosos da área de leitura, como Frank Smith, Josette } \\
\text { Jolibert, Jeanette Jacob e Elie Bajard. }\end{array}$ \\
\hline 6 & Alfabetização e letramento: Magda Soares e Chartier. \\
\hline 8 & Alfabetização e letramento: Magda Soares. \\
\hline 9 & $\begin{array}{l}\text { Organização do tempo; base curricular nacional; alfabetização e letramento: } \\
\text { Magda Soares. }\end{array}$ \\
\hline 10 & Concepções de linguagem e sujeito em Benjamin e Bakhtin. \\
\hline 11 & Certeau. Magda Soares. \\
\hline 12 & Psicogênese da língua de Ferreiro e Teberosky. \\
\hline 13 & Filosofia da linguagem de Bakhtin e pedagogia crítica de Paulo Freire. \\
\hline 14 & Perspectiva dialógica e interacionista: Jolibert; Bakhtin; Geraldi; e Soares. \\
\hline 15 & Teoria da Enunciação de Bakhtin; Vygotsky. \\
\hline 16 & Aquisição da escrita: Zorzi, Palangana e Spinillo. \\
\hline 18 & Aquisição da linguagem: Cruz e Magda Soares. \\
\hline 19 & Magda Soares e Colomer. \\
\hline 20 & Barrera e Maluf; consciência morfológica e consciência sintática. \\
\hline
\end{tabular}

Revista Exitus, Santarém/PA, Vol. 10, p. 01-25, e020032, 2020. 
Defectologia de Vygotsky e abordagem relativa à experiência da aprendizagem mediada (EAM) desenvolvida por Feverstein.

Fonte: Elaborado pelas autoras com base em levantamento nos sites da ANPED e do SciElo.

O referencial teórico mais utilizado é o conceito de letramento de Soares (2004), seguido pela psicogênese da língua escrita de Ferreiro e Teberosky (1985). Também foram localizados trabalhos fundamentados em Bakhtin (1988) e na Teoria Histórico-cultural.

Como comprovado por Ribeiro (2011) e Soares (1989), os estudos selecionados nesta pesquisa apresentam forte presença das áreas da Linguística e da Psicolinguística. As contribuições dessas áreas provocaram mudanças substanciais na concepção da aprendizagem da leitura e da escrita, especialmente as advindas do conceito de letramento. Nesse conceito é enfatizada a necessidade de se inserir, nos processos pedagógicos, as práticas sociais de uso da língua e também de se trabalhar com as diferentes competências linguísticas envolvidas nos usos da linguagem oral e escrita em diferentes contextos sociais.

Nas pesquisas apresentadas nas primeiras reuniões da ANPED, predomina o referencial teórico da psicogênese da língua escrita de Ferreiro e Teberosky (1985). Nas produções encontradas no SciELO, constatamos que nenhum referencial se destacou, caracterizando-se, assim, uma diversidade teórica. Isso nos leva a inferir que, no SciELO, predomina a abordagem multidisciplinar, enquanto na ANPED há maior ênfase na área da educação.

As metodologias utilizadas nos trabalhos selecionados variaram conforme os objetivos de cada pesquisa. É o que mostramos no Quadro 3.

Quadro 3 - Metodologias utilizadas nas pesquisas

\begin{tabular}{|c|l|}
\hline & \multicolumn{2}{|c|}{ Metodologia } \\
\hline 1 & $\begin{array}{l}\text { Pesquisa qualitativa, com proposta de intervenção colaborativa, cujo intuito foi } \\
\text { acompanhar uma turma de crianças de } 6 \text { anos em laboratório de informática de } \\
\text { escola pública em Belo Horizonte, Minas Gerais, durante um ano, em várias situações } \\
\text { que exigiam atividades de escritura e leitura na tela do computador. Os } \\
\text { procedimentos utilizados foram os de observação, anotação, filmagem e entrevistas. }\end{array}$ \\
\hline 2 & $\begin{array}{l}\text { Pesquisa qualitativa para avaliação de } 40 \text { crianças de duas turmas nas seguintes } \\
\text { atividades: ditado de palavras para verificação do nível de escrita, identificação de } \\
\text { letras, nomeação de letras e produção de letras, em três momentos distintos do ano }\end{array}$ \\
\hline
\end{tabular}

Revista Exitus, Santarém/PA, Vol. 10, p. 01-25, e020032, 2020. 


\begin{tabular}{|c|c|}
\hline & $\begin{array}{l}\text { ivo. A análise dos dados foi realizada conforme categorias da psicogênese da } \\
\text { crita. }\end{array}$ \\
\hline 3 & $\begin{array}{l}\text { Estudo de caso. Participaram da pesquisa seis professoras: três de cada escola } \\
\text { (seriada e ciclada), representando as três primeiras séries do ensino fundamental. Os } \\
\text { procedimentos foram: (1) realização de uma atividade diagnóstica (escrita de } \\
\text { palavras) com os alunos das três turmas do } 1^{\circ} \text { ciclo, no início e no final do ano letivo; } \\
\text { (2) análise documental das propostas curriculares de cada um dos municípios; (3) } \\
\text { entrevistas com as professoras; (4) observações de aulas das professoras participantes } \\
\text { da pesquisa. }\end{array}$ \\
\hline 4 & $\begin{array}{l}\text { Recorte de um estudo de caso de duas professoras atuantes em } 1^{\circ} \text { anos de } \\
\text { alfabetização. Foram realizadas observações de aulas nas duas salas selecionadas, } \\
\text { em dias alternados dos meses de novembro e dezembro, entrevistas individuais com } \\
\text { as professoras e todas as crianças. Analisou-se também o desempenho dos alunos em } \\
\text { expressão oral e escrita. Nesse recorte, constam dados de apenas uma professora. }\end{array}$ \\
\hline 5 & $\begin{array}{l}\text { Pesquisa do tipo etnográfico na qual foram utilizados os seguintes instrumentos: } \\
\text { entrevista semiestruturada com duas professoras, uma de cada ano, e análise do } \\
\text { caderno de português de duas crianças. }\end{array}$ \\
\hline 6 & $\begin{array}{l}\text { Participaram nove professoras dos três anos do } 1^{\circ} \text { ciclo de três instituições da Rede } \\
\text { Municipal de Ensino de Recife. Foram realizadas oito observações de jornadas de } \\
\text { aula completas em cada turma, totalizando } 72 \text { protocolos. Ao final do ano letivo, } \\
\text { cada uma das docentes foi entrevistada. A análise de dados foi classificada como } \\
\text { análise de conteúdo temático. }\end{array}$ \\
\hline 7 & $\begin{array}{l}\text { Pesquisa Interpretativa de cunho etnográfico. Foram realizadas } 13 \text { observações de } \\
\text { aulas de português de uma turma do } 2^{\circ} \text { ano do ensino fundamental entre os meses } \\
\text { de agosto e dezembro de } 2010 \text {. }\end{array}$ \\
\hline 8 & $\begin{array}{l}\text { Pesquisa qualiquantitativa. Os dados foram gerados de } 10 \text { observações consecutivas, } \\
\text { realizadas em seis turmas do } 1^{\circ} \text { ano do ensino fundamental de seis escolas públicas, } \\
\text { das três redes de ensino: três da rede municipal, duas da estadual e uma da federal. } \\
\text { As observações foram registradas por meio de notas de campo. }\end{array}$ \\
\hline 9 & $\begin{array}{l}\text { Pesquisa qualitativa. Foi analisada a interação dos alunos de uma turma de } 1^{\circ} \text { ano do } \\
\text { ensino fundamental ( } 6 / 7 \text { anos) com uma obra lobatiana. Foram adotados os } \\
\text { seguintes procedimentos: observação participante em doze aulas de literatura da } \\
\text { turma e entrevista com a professora. }\end{array}$ \\
\hline 10 & $\begin{array}{l}\text { Análise dos cadernos de planejamento de uma professora alfabetizadora entre os } \\
\text { anos de 1983-2000. Entrevistas. Cruzamento de duas fontes: cadernos de } \\
\text { planejamento e cartilhas. Mapeamento e identificação das cartilhas. }\end{array}$ \\
\hline 11 & $\begin{array}{l}\text { Participaram duas professoras alfabetizadoras que estavam na regência de turmas } \\
\text { do } 2^{\circ} \text { ano das séries iniciais do ensino fundamental da região metropolitana de } \\
\text { Recife. Procedimentos: entrevistas, observação de inspiração etnográfica e } \\
\text { entrevistas de autoconfrontação. }\end{array}$ \\
\hline 12 & $\begin{array}{l}\text { Procedimentos: a) observação de } 12 \text { jornadas completas de aula da prática } \\
\text { docente; b) entrevistas semiestruturadas com a professora no início e no final da } \\
\text { pesquisa e minientrevistas após as aulas; c) diagnose de leitura de palavras, de leitura } \\
\text { de textos, de escrita de palavras e de produção de textos com o intuito de subsidiar a } \\
\text { análise das estratégias docentes para lidar com os diferentes níveis de conhecimento } \\
\text { presentes na classe. Os níveis de escrita das crianças foram analisados de acordo } \\
\text { com a teoria da psicogênese da escrita e análise de conteúdo de Bardin. }\end{array}$ \\
\hline 13 & $\begin{array}{l}\text { Em colaboração com a professora, promoveram-se oficinas de alfabetização } \\
\text { mediadas pelo artesanato, o principal instrumento metodológico da pesquisa. Foram } \\
\text { realizados Círculos de "Artesanar" com quinze crianças do } 1^{\circ} \text { ano do ensino } \\
\text { fundamental de uma escola pública. Além de entrevistas dialógicas com as crianças } \\
\text { e com a professora foi realizada uma exposição dos artesanatos infantis. Como } \\
\text { registros, a gravação em áudio e em vídeo, fotografias e notas de campo. }\end{array}$ \\
\hline 14 & $\begin{array}{l}\text { Observação das práticas de ensino de leitura literária em cinco turmas ( } 1^{\circ} \text { ao } 5^{\circ} \text { ano) } \\
\text { entre os meses de abril e dezembro de } 2014 \text {. Cada turma foi observada por uma } \\
\text { semana letiva, durante todo o horário de aula. Além das práticas de sala de aula, }\end{array}$ \\
\hline
\end{tabular}

Revista Exitus, Santarém/PA, Vol. 10, p. 01-25, e020032, 2020. 


\begin{tabular}{|l|l|}
\hline & $\begin{array}{l}\text { foram observados os aspectos relativos à gestão e à estrutura escolar que interferem } \\
\text { na didática e no ensino de leitura: formação de professores; espaço da biblioteca } \\
\text { escolar, seu funcionamento e acervo disponível; gestão pedagógica, planejamento e } \\
\text { trabalho coletivo; avaliação da aprendizagem. }\end{array}$ \\
\hline 15 & $\begin{array}{l}\text { A pesquisa foi realizada com } 21 \text { alunos de uma turma do } 1^{\circ} \text { ano do ensino } \\
\text { fundamental de uma escola pública federal do Rio de Janeiro, no ano de } 2011 . \\
\text { Foram realizadas observações participantes e também foram entrevistados alguns } \\
\text { pais e a professora da turma. }\end{array}$ \\
\hline 16 & $\begin{array}{l}\text { Pesquisa observacional, descritiva e transversal, com participação de } 30 \text { crianças do } \\
3^{\circ} \text { ano do ensino fundamental I e suas mães. Entrevistas com mães e avaliação da } \\
\text { escrita das crianças. }\end{array}$ \\
\hline 17 & $\begin{array}{l}\text { O estudo contou com a participação de } 18 \text { pais ou responsáveis de crianças } \\
\text { atendidas no Estágio de Leitura/Escrita do Curso de Fonoaudiologia de uma } \\
\text { universidade pública. Consultas a prontuários das crianças e entrevistas } \\
\text { semiestruturadas. }\end{array}$ \\
\hline 18 & $\begin{array}{l}\text { Observações de sala de aula registradas em diário de campo, entrevista com a } \\
\text { professora e entrevistas com os alunos de } 1^{\circ} \text { ano. }\end{array}$ \\
\hline 19 & $\begin{array}{l}\text { Participaram do estudo } 28 \text { crianças portuguesas do } 1^{\circ} \text { ano do ensino básico. No início } \\
\text { do ano foram aplicadas as provas relativas ao conhecimento metalinguístico e à } \\
\text { consciência fonológica, morfológica e sintática. }\end{array}$ \\
\hline & $\begin{array}{l}\text { Perspectiva etnográfica, envolvendo dois estudos realizados em Minas Gerais. A } \\
\text { primeira pesquisa desenvolveu-se em } 2010, \text { na rede municipal de ensino de } \\
\text { Tiradentes. O procedimento foi o da observação de sala de aula durante } 47 \text { dias. A } \\
\text { segunda ocorreu, em } 2013, \text { na rede municipal de Juiz de Fora. O procedimento } \\
\text { também foi o da observaçãodurante } 45 \text { dias ao longo do primeiro semestre letivo. O } \\
\text { contraste entre os dois foi utilizado como estratégia de análise. }\end{array}$ \\
\hline 21 & $\begin{array}{l}\text { Foram organizadas } 10 \text { oficinas com cerca de } 30 \text { a } 40 \text { minutos cada, uma vez por } \\
\text { semana. Pesquisa qualitativa, com observação participante e entrevista } \\
\text { semiestruturada com a professora e com as mães. }\end{array}$ \\
\hline
\end{tabular}

Fonte: Elaborado pelas autoras com base em levantamento nos sites da ANPED e SciElo.

Quanto às escolhas metodológicas, a maior parte das pesquisas se autodenominou de qualitativa; apenas duas denominaram-se quantiqualitativas.

O principal instrumento de coleta de dados foi a entrevista semiestruturada. No entanto, em vários trabalhos, foram utilizadas observações em sala de aula, organizadas de diferentes formas e com durações distintas. Em algumas pesquisas, foram adotadas intervenções em salas de aula.

Para além da entrevista e da observação, chama a atenção a diversidade de procedimentos para a produção dos dados: uso do computador, produção de artesanato e filmagem com autoconfrontação.

As professoras aparecem como as principais participantes, mas as pesquisas envolveram crianças com frequência, sugerindo a ampliação do 
olhar dos pesquisadores para os principais sujeitos do processo de alfabetização.

No que tange ao tratamento dos dados, predomina Bardin (1977) com sua teoria da análise de conteúdo.

Quanto às temáticas, os dados foram organizados em seis eixos temáticos, conforme Quadro 4.

Quadro 4: Temáticas investigadas

\begin{tabular}{|l|l|c|}
\hline \multicolumn{1}{|c|}{ Eixo temático } & \multicolumn{1}{|c|}{ Autores } & $\begin{array}{c}\text { No de } \\
\text { trabalhos }\end{array}$ \\
\hline Leitura e Escrita & $\begin{array}{l}\text { Gaiolas e Martins (2017); Aire (2017); Leite, Bittencourt e Silva } \\
\text { (2015); Ferreira, Silva e Queiroga (2014); Gonçalves (2013); } \\
\text { Correia (2013); Glória e Frade (2011); Leite (2011). }\end{array}$ & 08 \\
\hline $\begin{array}{l}\text { Práticas } \\
\text { Pedagógicas de } \\
\text { Alfabetização }\end{array}$ & $\begin{array}{l}\text { Macedo, Almeida e Tibúrcio (2017); Nascimento (2017); Sá e } \\
\text { Pessoa (2015); Gama (2015); Santos e Tassoni (2015); Souza } \\
\text { e Cardoso (2012); Cruz e Alburquerque (2012). }\end{array}$ & 07 \\
\hline Língua Portuguesa & Magalhães e Muller (2015); Oliveira (2013). & 02 \\
\hline Mediação & Dionísio e Vectore (2017); Travassos (2015). & 02 \\
\hline Planejamento & Vieira (2015). & 01 \\
\hline Letramento & Melo e Magalhães (2013). & 01 \\
\hline
\end{tabular}

Fonte: Elaborado pelas autoras com base em levantamento nos sites da ANPED e SciElo.

Verificamos que, nos artigos que compõem o eixo temático Leitura e Escrita, predominou a questão da aprendizagem da escrita, com foco nos seguintes tópicos: influência da família no ato de aprender a escrever; percepção das crianças sobre a linguagem escrita; fatores socioculturais que envolvem o processo de aquisição da linguagem escrita; papel da aquisição do sistema fonológico no desenvolvimento do sistema ortográfico pela criança; tecnologia na educação como facilitadora na aquisição do SEA (Sistema de Escrita Alfabética).

Coincidindo com o que aponta Ribeiro (2011), os dados deste levantamento indicam que a maior preocupação dos autores na questão da alfabetização continua sendo a aquisição da escrita.

Dois trabalhos a respeito da leitura e da escrita referem-se à emancipação no ato de ensinar. Um deles é o de Gaiolas e Martins (2017),

\footnotetext{
${ }^{3}$ Alguns trabalhos apresentam mais de um objeto de pesquisa. Contudo, visando melhor compreensão, decidimos eleger um tema central para cada um, tomando o assunto em destaque na pesquisa como categoria de classificação no eixo temático.
}

Revista Exitus, Santarém/PA, Vol. 10, p. 01-25, e020032, 2020. 
cujos objetos de pesquisa são o conhecimento metalinguístico e a aprendizagem da leitura e da escrita. Os resultados dessa pesquisa demonstraram que, quando o desenvolvimento cognitivo, a memória verbal e as habilidades da mãe são controlados, os resultados nas provas de consciência fonológica, morfológica e sintática são mais elevados. Outro é o de Aire (2017), que registra que o ato responsável diante da formação das palavras despertou, completou e até transformou a leitura do mundo das crianças de forma não mecanicista.

Leite, Bittencourt e Silva (2015) identificaram a influência de fatores socioculturais no processo de aquisição da linguagem escrita em uma amostra composta por pessoas com baixa escolaridade e baixa renda. As autoras averiguaram que muitos pais, embora tivessem relatado que possuíam em casa algum tipo de material de leitura, não eram referências leitoras: grande parte $(44,4 \%)$ não tinha $\circ$ hábito de leitura. Também averiguaram que os filhos tinham acesso à tecnologia, mas a mensagem pronunciada muitas vezes não era compreendida nem explicada pelos pais.

De forma semelhante, Silva, Ferreira e Queiroga (2014) buscaram investigar a relação do grau de instrução materno com a escrita das crianças. Concluíram que a aprendizagem da escrita em seus aspectos mais específicos, como o desenvolvimento do esquema narrativo, sofre influência de fatores sociais, como o da escolaridade materna.

Gonçalves (2014) teve por objetivo conhecer as concepções que crianças elaboram sobre o processo de alfabetização, antes e depois de serem alfabetizadas. Constatou que o aprendizado da leitura e da escrita altera os modos de pensar e os dizeres das crianças e que os conhecimentos específicos sobre o sistema de escrita lhes permitem realizar novas operações metalinguísticas e metacognitivas.

Correia (2013) é o único a tratar somente da leitura, analisando as concepções de leitura de professoras alfabetizadoras e sua materialização nos modos como ensinam a ler. Em suas conclusões, revela que as concepções de leitura dessas professoras exerciam grande influência na formação do conceito de leitura como treino, como ato de pronúncia, em 
vez de aproximar os alunos da concepção de leitura como atribuição de sentido e prática cultural.

Glória e Frade (2011) constataram que, ao usar o computador como um suporte de escrita, as crianças mobilizam saberes diferentes dos da escrita no papel, refletindo, por exemplo, que, para o uso da letra maiúscula, é necessário acionar a tecla caps lock. As autoras entendem que se faz necessário compreender o computador como um suporte multimodal.

Leite (2011) sugere que o conhecimento das letras não determina a compreensão do princípio fonológico da escrita alfabética, entretanto algumas habilidades de reflexão sobre os sons por parte de algumas crianças podem facilitar o processo de alfabetização, ao passo que outras crianças somente avançam à medida que alcançam o nível alfabético.

Quanto ao eixo Práticas Pedagógicas de Alfabetização, Cruz e Albuquerque (2012) analisaram a construção dessas práticas na perspectiva do letramento em sistemas de ensino organizados em série e em ciclos. Nas duas escolas, predominou a realização de atividades de forma coletiva e individual. Os autores destacam que as escolas apresentaram resultados semelhantes e que a metodologia empregada decorre das condições reais de desenvolvimento da prática de alfabetização.

Souza e Cardozo (2012), além das práticas de alfabetização, abordaram o tema do letramento. Consideraram que o sucesso da professora decorre de seu trabalho na perspectiva do letramento e destacaram algumas razões para isso: a ênfase no trabalho com textos que faziam sentido para os alunos e nos quais eles podiam reconhecer os propósitos da leitura e da escrita; o uso de variados textos, como parlendas, trava-línguas, poemas e músicas; a prática de antecipar conhecimentos sobre os textos lidos, interpretando-os e produzindo-os.

Gama (2015) analisou as relações entre a construção cotidiana de práticas docentes na alfabetização e a formação continuada vivenciada por professoras alfabetizadoras em uma rede pública municipal. $O$ estudo possibilitou a percepção de como se dão as construções de escolhas didáticas e das crenças subjacentes das professoras e associou-as às 
contribuições da formação continuada e às trajetórias na rede de ensino. Mesmo quando não havia referência explícita à formação continuada, o vocabulário do contexto dos eventos de formação estava presente. O conjunto de saberes das professoras, singulares entre si e advindos das escolhas rotineiras, eram a representação do estilo de lecionar de cada uma.

Sá e Pessoa (2015), além do tema prática de alfabetização, consideram a heterogeneidade das aprendizagens. Esses autores identificaram três estratégias docentes para lidar com a heterogeneidade de aprendizagem das crianças: atividades diferenciadas realizadas coletivamente; atividades diferenciadas realizadas em grupo ou em duplas; atividades diferenciadas realizadas individualmente. As estratégias de diversificação de atividades e os modos de acompanhamento docente, flexíveis e atentos às diferenças individuais, tinham como pressuposto o atendimento à heterogeneidade de aprendizagens da turma. No entanto, eles notaram também que o critério de agrupamento das crianças para a realização das atividades em grupo e em duplas era guiado pelo princípio da homogeneidade e não se modificava conforme os objetivos das atividades propostas. A professora não parecia ter como pressuposto pedagógico que a mescla de níveis de aprendizagem a auxiliaria a se valer da heterogeneidade de conhecimentos para potencializar as aprendizagens infantis.

Nascimento (2017) investigou se as práticas de ensino de leitura literária nos anos iniciais do ensino fundamental na rede estadual paulista têm contribuido para formar leitores capazes de construir sentidos para os textos lidos. Os dados demostram que houve pouca variedade de atividades de ensino de leitura nas aulas de todas as turmas. Quase não houve tratamento de aspectos estilísticos ou de recursos expressivos contidos nos textos lidos. $O$ autor menciona que havia a tentativa de realizar práticas inovadoras, mas a incorporação de novidades ou de práticas didáticas supostamente transformadoras acontecia em um esquema de ensino tradicional. 
Santos e Tassoni (2015) examinaram como a proposta do material didático do Programa Ler e Escrever foi vivenciada pelos alunos e pela professora de uma sala de $1^{\circ}$ ano do ensino fundamental em uma escola estadual de Campinas. Os resultados apontam o anseio dos alunos por compreender o funcionamento e a finalidade da escrita, o apoio fundamental do material didático para a aquisição satisfatória da linguagem escrita e também a importância da mediação. $O$ fato de alguns alunos explicarem o que aprendiam sobre os costumes e a cultura indígena levou as autoras a inferir que a aprendizagem de conhecimentos relacionados a contextos e culturas diferentes atrai os alunos, levando-os a se reconhecer na realidade em que vivem e a se considerar parte da natureza e da cultura.

Macedo, Almeida e Tibúrcio (2017) tiveram como objetivo identificar as práticas de leitura e escrita com as crianças de seis anos no ensino fundamental. Concluíram que o trabalho das professoras contém semelhanças e diferenças, sendo centrado na apropriação do sistema de escrita e não difere das práticas já comuns aos anos iniciais. Nenhuma segue a proposta do livro, nenhuma ensina as múltiplas linguagens, nem prioriza o lúdico e a brincadeira nos processos de construção do conhecimento das crianças, pressupostos defendidos por estudiosos da infância.

No eixo temático Língua Portuguesa, Magalhães e Muller (2015) e Oliveira (2013) discorrem sobre como o tempo destinado ao ensino da língua tem sido empregado na alfabetização. Constatam que nem todos os eixos linguísticos são foco de atenção do professor alfabetizador e que a baixa produção de textos escritos e falta de atenção à oralidade permeiam o estudo da língua portuguesa nas escolas pesquisadas. Ambos apontam que há maior incidência de atividades de apropriação do sistema de escrita alfabética, que há predominância da leitura dos textos pelos professores e que há ausência de articulação com a compreensão da escrita. A produção textual individual é mais frequente durante as aulas do que a produção com o auxílio do professor. 
Em relação ao eixo temático Mediação, Dionísio e Vectore (2017) e Travassos (2015) constatam a importância da mediação no desenvolvimento da leitura e da escrita e ressaltam que, com a mediação adequada, é possível obter sucesso na aprendizagem escolar. Desse eixo, o artigo 21 é o único que aborda a alfabetização de crianças com deficiência. O objetivo da pesquisa foi avaliar oficinas de intervenção mediacional na aprendizagem do Braille por crianças cegas em uma sala de educação especial de Uberaba. As autoras constataram que a proposta desenvolvida nas oficinas oportunizou que as crianças cegas criassem uma relação significativa entre leitura e escrita.

No eixo Planejamento, o único trabalho é o de Vieira (2015), que mapeou, entre os anos 1983 e 2000, os livros destinados ao ensino inicial da leitura e da escrita e usados como apoio na preparação das aulas. Analisando como esse uso aparecia nos cadernos de planejamento de uma professora alfabetizadora, concluiu que, nesses cadernos, há um modelo a ser seguido pela professora. Os planos de aula indicam que o processo de alfabetização está estritamente ligado à aquisição de uma técnica, efetivada por meio da memorização e repetição.

Por fim, no eixo Letramento, Melo e Magalhães (2013) buscaram entender como a alfabetização na perspectiva do letramento tem acontecido em ambiente escolar. Por meio da observação de atividades realizadas em sala de aula, as pesquisadoras identificaram a ênfase nos processos de alfabetização e letramento. Os dados foram gerados com base em observações e notas de campo e, por um lado, revelaram que a professora valorizava o processo de letramento e que fazia isso com competência. Por outro lado, porém, revelaram que o trabalho com a apropriação do sistema de escrita alfabética é menos sistemático.

A partir dos dados apresentados podemos afirmar, em concordância com Lupassa (2015) que as produções dos pesquisadores estão condicionadas ao contexto teórico do período em que foram produzidas e pela orientação filosófica que fundamentaram as investigações. Desta forma é possível verificar uma busca dos investigadores pelas práticas mais exitosas 
nos processos de ensino e, ao mesmo tempo, críticas ao que consideram problemas para a garantia desse êxito, a partir do referencial teórico de cada pesquisador.

Neste sentido, foi possível perceber o interesse dos pesquisadores por diferentes aspectos do processo de alfabetização, desde o contexto familiar e sociocultural das crianças, planejamento das professoras, métodos de ensino, até as relações pedagógicas em sala de aula.

Entretanto, assim como apontado por Ribeiro (2011) e Lupassa (2015) ainda há muito por se investigar nesse campo, considerando as necessidades de aprendizagem que ainda não são atendidas pelas escolas.

\section{CONSIDERAÇÕES FINAIS}

Neste texto, por meio do levantamento e da análise de 21 artigos direcionados ao tema, buscamos entender como a alfabetização tem sido estudada nos últimos anos no Brasil e procuramos identificar as concepções e as perspectivas que sustentam a produção teórica na área, bem como lacunas que necessitam de maiores investimentos em termos de pesquisa.

Resumindo as características dos trabalhos analisados, podemos afirmar que as pesquisas sobre alfabetização estão concentradas nas regiões Sudeste e Nordeste, são realizadas por mulheres, em programas de pós-graduação de universidades públicas e ainda recorrem aos principais expoentes teóricos do campo desde os anos 1980: Ferreiro e Teberoski e Soares.

Quanto ao método, a maioria dos artigos são resultantes de pesquisas qualitativas, nas quais foram utilizados diferentes instrumentos de produção de dados, com predomínio de entrevistas. Professoras e crianças são as participantes privilegiadas nos estudos analisados.

A análise dos dados revela uma grande heterogeneidade temática. Quanto mais a alfabetização é explorada em sua complexidade, maior é a multiplicidade de enfoques e mais amplo o leque dos aspectos analisados nas pesquisas. Embora predominem pesquisas sobre a aprendizagem da escrita, o número significativo de trabalhos que se dedicaram a investigar as 
práticas pedagógicas na alfabetização aponta para um equilíbrio entre o olhar sobre a criança que aprende e sobre o professor que ensina, o que pode indicar uma superação da dicotomia entre ensino e aprendizagem no trabalho docente.

Tal dicotomia foi construída no processo de apropriação pelo campo escolar das contribuições de Ferreiro e Teberosky (1985), responsáveis pela transformação do olhar sobre a criança em processo de alfabetização. De passiva, dentro do processo de aprendizagem, a criança passou a ser observada e estudada em detalhes, analisada e respeitada como sujeito ativo (RIBEIRO, 2011). Entretanto, embora se tenha atribuído um papel ativo ao aluno como sujeito da própria aprendizagem, ao professor foi atribuído um papel passivo que tende a transformá-lo naquele que apenas acompanha o processo de aprendizagem da criança.

As contribuições dos estudos sobre o letramento, por meio da explicitação das competências linguísticas envolvidas no processo de alfabetização, bem como a defesa do professor como aquele a quem compete dirigir o processo de ensino, preconizada pela psicologia históricocultural, parecem ter contribuído para que os pesquisadores tenham buscado olhar para outros aspectos do processo de alfabetização. A preocupação passou a ser a de entender como se dá o processo pedagógico em sala de aula, que aspectos da linguagem são trabalhados pelos professores e que tipos de ferramentas e mediações são utilizados.

Em relação às lacunas, consideramos importante destacar o exíguo número de trabalhos que abordam a alfabetização de crianças com deficiência, o uso da tecnologia e a alfabetização em escolas do campo. Isso aponta para a necessidade de maiores investimentos nessas temáticas.

Destacamos ainda a ausência de estudos sobre a alfabetização em contextos de diversidade cultural, tais como as comunidades indígenas e quilombolas, e sobre a avaliação do processo de ensino e aprendizagem da língua escrita. Consideramos que essa ausência constitui as maiores lacunas a serem preenchidas por novas investigações. 
Por fim, sugerimos que novas revisões sobre a temática incluam a produção em formato de livros. Tais veículos favorecem o acesso às produções de pesquisadores e grupos de pesquisa com experiência no estudo da temática e podem agregar análises históricas e de maior abrangência.

\section{REFERÊNCIAS}

BAKHTIN, M. Marxismo e filosofia da linguagem. São Paulo: Hucitec, 1988.

BARDIN, L. Análise de conteúdo. Lisboa: Edições 70,1977.

FERREIRO, E.; TEBEROSKY, A. A Psicogênese da Língua Escrita. Porto Alegre: Artes Médicas, 1985.

GOULART, C.; SCHWARTZ, C. M.; MACIEL, F. Alfabetização, leitura e escrita: uma análise das pesquisas apresentadas no período 2002-2006 na (ANPED)/GT-10. Cadernos de Pesquisa em Educação, n. 41, p. 15-39, 2015.

KLEIMAN, A. B. (Org.). Os significados do letramento: uma nova perspectiva sobre a prática social da escrita. Campinas, SP: Mercado de Letras, 1995.

LUPASSA, E. C. Aprendizagem da leitura e escrita: o estado da arte no período de 2010 a 2014. 2015. 88p. Dissertação (Mestrado em Fonoaudiologia): Pontifícia Universidade Católica de São Paulo. São Paulo, 2015.

LURIA, A. R. O desenvolvimento da escrita na criança. In: VYGOTSKY, L. S. et al. Linguagem, desenvolvimento e aprendizagem. 12 ed. São Paulo: Ícone/USP, 2012. p.143-190.

MORTATTI, M. R. L. História dos métodos de alfabetização no Brasil. Seminário Alfabetização e Letramento em Debate. Brasília: MEC, v. 1, n. 1, p1-15, 2006. Disponível em:

<http://portal.mec.gov.br/seb/arquivos/pdf/Ensfund/alf_mortattihisttextalfbbr .pdf>. Acesso em 13 abr. 2018.

RIBEIRO, A. R. P. S. Alfabetização: o estado da arte em periódicos científicos (1987-2008). 201 1. 186p. Dissertação (Mestrado em Educação). Universidade Estadual de Campinas, Campinas, 2011.

SOARES, M. Alfabetização no Brasil: o estado do conhecimento. Brasília: INEP/REDUC, 1989. 
SOARES, M. Letramento: um tema em três gêneros. Belo Horizonte: Autêntica, 1998.

SOARES, M. Letramento e alfabetização: as muitas facetas. Revista Brasileira de Educação-ANPED, n. 25. Rio de Janeiro: Autores Associados, p. 5-17, 2004.

TFOUNI, L.V. Letramento e Alfabetização. São Paulo: Cortez, 2010.

TULESKI, S. C.; CHAVES, M. Ler e escrever: da necessidade de ensinar e em defesa da superação de visões organicistas das dislexias, disgrafias e disortografias. In: FACCl, M. G. D.; MEIRA, M. E. M.; TULESKI, S. C. (Org.) . A exclusão do "incluídos": uma crítica da psicologia da educação à patologização e medicalização dos processos educativos. Maringá: EDUEM, 2011. p. 197-227.

VIGOTSKII, L. S. Aprendizagem e desenvolvimento intelectual na idade préescolar. In: VYGOTSKY, L. S. et al. Linguagem, desenvolvimento e aprendizagem. 12 ed. São Paulo: Ícone/USP, 2012. p.103-117.

ZIBETTI, M. L.; SOUZA, M. P. Apropriação e mobilização de saberes na prática pedagógica: contribuição para a formação de professores. Educação e Pesquisa, São Paulo, v.33, n.2, p. 247-262, 2007.

\section{REFERÊNCIAS DO LEVANTAMENTO}

AIRE, F. S. L. Alfabetização emancipadora com crianças: "artesanar" leituras da palavra mundo. In: 38 Reunião Anual da Associação Nacional de Pósgraduação e Pesquisa em Educação, 2017, São Luiz -MA. Anais... São Luiz: GT10, ANPEd, 2017.

CORREIA, J. R. A concepção de leitura de professoras alfabetizadoras e a sua influência no ensino do ato de ler. In: $36^{a}$ Reunião Anual da Associação Nacional de Pós-graduação e Pesquisa em Educação, 2013, Goiânia -GO. Anais... Goiânia: GT10, ANPEd, 2013.

CRUZ, M. do C. S.; ALBUQUERQUE, E. B. C. de. A relação entre as práticas de alfabetização e as aprendizagens das crianças nos três anos iniciais do ensino fundamental em escolas organizadas em série e em ciclos. In: $35^{a}$ Reunião Anual da Associação Nacional de Pós-graduação e Pesquisa em Educação, 2012, Porto de Galinhas -PE. Anais... Porto de Galinhas: GT10, ANPEd, 2012.

DIONISIO, A. M. P.; VECTORE, C. Intervenção Mediacional na aprendizagem do Braille: um estudo com crianças deficientes visuais. Psicol. Esc. Educ. v. 21 , n.3, p.549-560, 2017.

FERREIRA, A. de A.; SILVA, A. C. F. da; QUEIROGA, B. A. M. de. A aprendizagem da escrita e a escolaridade materna. Rev. CEFAC. v. 16, n.2, p.446-456, 2014. 
FERREIRA, A. F.; NASCIMENTO, I.; FONTAINE, A. M. O papel do professor na transmissão de representações acerca de questões vocacionais. Revista Brasileira de Orientação Profissional, São Paulo, v. 10, n. 2, dez. 2009.

GAIOLAS, M. S.; MARTINS, M. A. Conhecimento metalinguístico e aprendizagem da leitura e da escrita. Aná. Psicológica. v. 35, n.2, p.117-124, 2017.

GAMA, Y. M. S. Construções cotidianas de práticas de alfabetização e o ensino sistemático da escrita: elementos da formação continuada mobilizados por professoras. In: $37^{a}$ Reunião Anual da Associação Nacional de Pós-graduação e Pesquisa em Educação, 2015, Florianópolis -SC. Anais... Florianópolis: GT10, ANPEd, 2015.

GLÓRIA, J. S.; FRADE, I. C. A. da S. A alfabetização e sua relação com o uso do computador: o suporte digital como mais um instrumento de ensinoaprendizagem da escrita. 201 1. In: 34 Reunião Anual da Associação Nacional de Pós-graduação e Pesquisa em Educação, 2011, Natal- RN. Anais... Natal: GT10, ANPEd, 2011.

GONCALVES, A. V. Alfabetização: o olhar das crianças sobre o aprendizado da linguagem escrita. Cad. CEDES. v. 33, n.89, p.125-140, 2013.

LEITE. T. M. S. B. R. O conhecimento de letras e sua relação com a aprendizagem da escrita alfabética. In: $34^{a}$ Reunião Anual da Associação Nacional de Pós-graduação e Pesquisa em Educação, 2011, Natal- RN.

Anais... Natal: GT10, ANPEd, 2011.

LEITE, K. K. de A.; BITTENCOURT, Z. Z. L. de C.; SILVA, I. R. Fatores socioculturais envolvidos no processo de aquisição da linguagem escrita. Rev. CEFAC. v. 17, n. 2, p. 492-501, 2015.

MACEDO, M. S. A. N.; ALMEIDA, A. C. de; TIBURCIO, A. P. do A. Práticas de alfabetização com crianças de seis anos no ensino fundamental: diferentes estratégias, diferentes concepções. Cad. CEDES. v. 37, n.102, p. 219-236, 2017.

MAGALHÃES, L. M.; MULLER, A.A. de O. O ensino da língua portuguesa na alfabetização inicial: tempos e contratempos. In: $37^{a}$ Reunião Anual da Associação Nacional de Pós-graduação e Pesquisa em Educação, 2015, Florianópolis -SC. Anais... Florianópolis: GT10, ANPEd, 2015.

MELO, T. T. M. de; MAGALHÃES, L. M. O desafio do "alfabetizar letrando" em sala de aula: um estudo de caso. In: $36^{a}$ Reunião Anual da Associação Nacional de Pós-graduação e Pesquisa em Educação, 2013, Goiânia-Go. Anais... Goiânia: GT10, ANPEd, 2013.

NASCIMENTO, I. S. do. Práticas de ensino de leitura literária nos anos iniciais: interações opacas, sentidos dissipados. In: $38^{a}$ Reunião Anual da Associação 
Nacional de Pós-graduação e Pesquisa em Educação, 2017, São Luiz -MA. Anais... São Luiz: GT10, ANPEd, 2017.

OLIVEIRA, S. A. de. Leitura, compreensão e produção textuais: progressão desses eixos de ensino de língua portuguesa no $1^{\circ}$ ciclo. In: $36^{a}$ Reunião Anual da Associação Nacional de Pós-graduação e Pesquisa em Educação, 2013, Goiânia-GO. Anais... Goiânia: GT10, ANPEd, 2013.

PINTO, H. R; TAVEIRA, M. C.; FERNANDES, M. E. Os professores e o desenvolvimento vocacional dos estudantes. Revista Portuguesa de

Educação, Braga, Universidade do Minho, v. 16, n. 1, p. 37-58, 2003.

QUADROS, A. L. et al. Os professores que tivemos e a formação da nossa identidade como docentes: um encontro com nossa memória. Ensaio Pesquisa em Educação em Ciências, v. 7, n. 1, p. 1-8, 2005.

SÁ, C.PESSOA; A.R.G. Práticas de alfabetização em turmas multisseriadas: estratégias docentes para lidar com a heterogeneidade de aprendizagens. In: 37a Reunião Anual da Associação Nacional de Pós-graduação e Pesquisa em Educação, 2015, Florianópolis -SC. Anais... Florianópolis: GT10, ANPEd, 2015.

SANTOS, T.C.; TASSONI, E. C. M. As práticas pedagógicas e o material didático do Programa Ler e Escrever no $1^{\circ}$ ano do ensino fundamental. Rev.

Bras. Estud. Pedagog. v. 96, n.242, p. 79-95, 2015.

SOUZA, I.P.M.; CARDOSO, C.J. Práticas de alfabetização e letramento: o fazer pedagógico de uma alfabetizadora bem sucedida. In: 35 $5^{a}$ Reunião Anual da Associação Nacional de Pós-graduação e Pesquisa em Educação, 2012, Porto de Galinhas -PE. Anais... Porto de Galinhas: GT10, ANPEd, 2012.

TRAVASSOS, S. Da sala de Dona Benta para a sala de aula: contribuições para pensar a mediação da leitura literária na escola. In: 37a Reunião Anual da Associação Nacional de Pós-graduação e Pesquisa em Educação, 2015, Florianópolis -SC. Anais... Florianópolis: GT10, ANPEd, 2015.

VIEIRA; C. M. Os livros para o ensino inicial da leitura e da escrita utilizados como apoio na preparação das aulas: um estudo a partir de cadernos de planejamentos de uma professora alfabetizadora (1983-2000). In: 37a Reunião Anual da Associação Nacional de Pós-graduação e Pesquisa em Educação, 2015, Florianópolis -SC. Anais... Florianópolis: GT10, ANPEd, 2015.

Recebido em: 16 de agosto de 2019

Aprovado em: 13 de janeiro de 2020 